\title{
NATURE'S FLUCTUATING COLOUR CAPTURED ON CANVAS?
}

\author{
F. SCHENK \\ Birmingham City University, England.
}

\section{ABSTRACT}

For centuries artists and natural scientists have been captivated by the colour changing effects of iridescence. Producing brilliant flashes of colour in the natural world, the phenomenon is best known in the displays of 'living jewels', e.g. tropical birds and butterflies, where the colour perceived changes with viewing angle. Such striking effects are not produced by chemical pigments but by complex physical structures interplaying with light. Until now, artists have tried to capture these luminous, oscillating colours with varying degrees of success. However, for the first time, latest advances in 'pigment' technology offer artists the exciting, but challenging, potential to introduce the full spectacle of iridescence into painting. These 'pigments' (developed with lucrative industrial applications in mind) currently remain restricted to commercial usage. The major drawback seriously impeding their advancement in art is that they do not adhere to colour theory as applied in painting. Having worked on adapting iridescent technology from its inception, gradual emergence and now rapid expansion, the author traces the sustained effort necessary on her part to overcome the many inherent challenges. Interweaving the findings of art theory, physics and personal studio practice, an attempt is made to position the new technology within the wider discourse on colour. And readers are furnished with an increased understanding of the scientific and aesthetic principles governing iridescence.

Keywords: colour theory, interference flakes, iridescence, optical physics, painting.

\section{INTRODUCTION: MULTIFACETED 'RAINBOW' HUES}

The fluctuating colours of 'living jewels', such as exotic beetles, butterflies and birds have always captivated man. To our ancestors, these luminous creatures appeared to have magical properties, playing a major role in the mythologies of ancient civilisations. Most noteworthy in this context is Iris, the bird-winged messenger of the Olympian Gods and personification of the rainbow, immortalised in the very word 'iridescence'. Following Newton's seminal double prism experiment, which proved that white light consists of all the colours of the rainbow, the science of physics has continued to reveal new dimensions to the aesthetics and mystical qualities initially assigned to iridescence by the Ancients. However, it was not until the mid-20th century that scanning electron microscopy allowed observation at a nano-scale, thereby finally proving beyond doubt what the Ancients had intuitively believed. The colours of the rainbow and iridescence are indeed inextricably linked. Both phenomena are caused by light interacting with transparent colourless matter [1]. A rainbow is created when the water droplets, like Newton's prism, split white light into its components - the colours of the spectrum. Layered nano-structures found in iridescent bird-feathers also act as light splitters, making (via constructive interference) certain pure spectral colours visible [2]. Accelerated scientific research into Nature's optical devices has, since the millennium, led to the manufacture of an everexpanding range of innovative iridescent flakes [3]. Because of their novel multi-layered structure, generating fluctuating colour, we can finally begin to creatively explore Nature's iridescence in art.

In tandem, a new academic field dedicated to iridescence has emerged. Scientists from diverse backgrounds (and subsequently artists) have begun to stake the nascent territory. In so doing they reaffirm what the physicist and philosopher Von Weizsäcker believes: namely, that colour is 'homeless' or rather - 'at home in a kind of no man's land bordered by physics, psychology, philosophy and art' [4]. Physics and art, disciplines located on either side of that border, have developed surprisingly similar attitudes that undervalue colour. The physicist Simon [2] laments that: 'Modern scientific thinking as first established in the seventeenth century has long used color as a classic

(C) 2009 WIT Press, www.witpress.com

ISSN: 1755-7437 (paper format), ISSN: 1755-7445 (online), http://journals.witpress.com DOI: 10.2495/DNE-V4-N3-274-284 
example of a "subjective," or secondary, quality, as opposed to form, which was considered an "objective," or primary quality.' Arguing along similar lines, the artist and theorist Batchelor traces the supremacy attributed in the Arts to disegno (palpable form/line) over colore (intangible colour) back to antiquity and the belief that objects somehow remain unchanged in substance if their colour was removed. He concludes that Chromophobia - a fear of corruption or contamination through colour - has always lurked within Western culture. Chromophobia adopts two guises: one denounces colour as alien (i.e. primitive, feminine, oriental, narcotic) and therefore dangerous; the other marginalises colour as superficial and cosmetic - 'a secondary quality of experience, and thus unworthy of serious consideration ... either way, colour is routinely excluded from the higher concerns of the Mind. It is other to the higher values of Western culture' [5].

By the 1960s, Von Weizsäcker [4] was suggesting that the old scientific theory of separating all phenomena according to their objective or subjective qualities could no longer be justified. Colour in all its manifestations is one phenomenon and no sharp distinction can be made between its purely physical and purely aesthetic aspects. Embracing the tenet of his insightful analysis, this paper interweaves the findings of physics, art theory and personal studio practice.

\section{THE LEGACY OF CHEMICAL PIGMENTS}

Gage [6] recently stated: 'Any account of colour in art must begin with the belief, which dominated Western culture for centuries . . . that colours are of two distinct types, those that are stable attributes of material substances, and those that are "accidental", such as the evanescent colours of the rainbow and the colours of some birds' feathers, which change according to the viewpoint of the spectator.' The 'stable' colours of material substances associated with chemical pigments (predominant both in Nature and the man-made environment) have long been the preoccupations of painters. It is on this type of pigment, traditionally used in paints, that artistic colour theories and the rules of subtractive colour mixing are based. Demonstrably, however, chemical pigments appear dull in comparison to the iridescent beams encountered in Nature and change neither colour nor brightness even when viewed from different angles. They absorb particular wavelengths of incoming white light. The colour impression is the remaining part of the light. When the primaries red, yellow and blue are combined, the mixture becomes darker with each colour added. More and more light is subtracted until black results. On that path towards darkness lies - grey.

\subsection{Grey: the anti-colour}

Paradoxically the author's journey towards iridescence began with grey. In the late 1990s, I embarked on a series of portraits based on Gerhard Richter's monochromatic photo-paintings. Taking on his mantle, I appropriated selected biographical photos from Richter's personal collection in his 'The Daily Practice of Painting' (1995). Richter himself has created copies of photographs seemingly devoid of personal experience, vision and style, thereby questioning widespread views of what constitutes a 'masterpiece' and indeed a 'master'. In contrast, my series reveals Richter posing, continuously taking centre stage, and as such reinforcing the rather clichéd image of the male artist as the mediator and lonely, pensive thinker (Fig. 1). Yet, markedly, my Richter series seeks to simultaneously present a stranger caught in the slow process of aging - a momento mori.

Imposing a 'mechanical', 'detached' photographic style on to subjects such as transience and death may seem alienating at first. But, at closer inspection, the fertile 'contradictions' intrinsic to Richter's work become rather intriguing. An early diagnosis suggests that we are dealing with a severe case of Chromophobia here. Richter claims that he pursues 'no programme, no style, no direction' [7] - a nihilist stance associated with the 'non-colour' grey. 'Grey is the welcome and only 


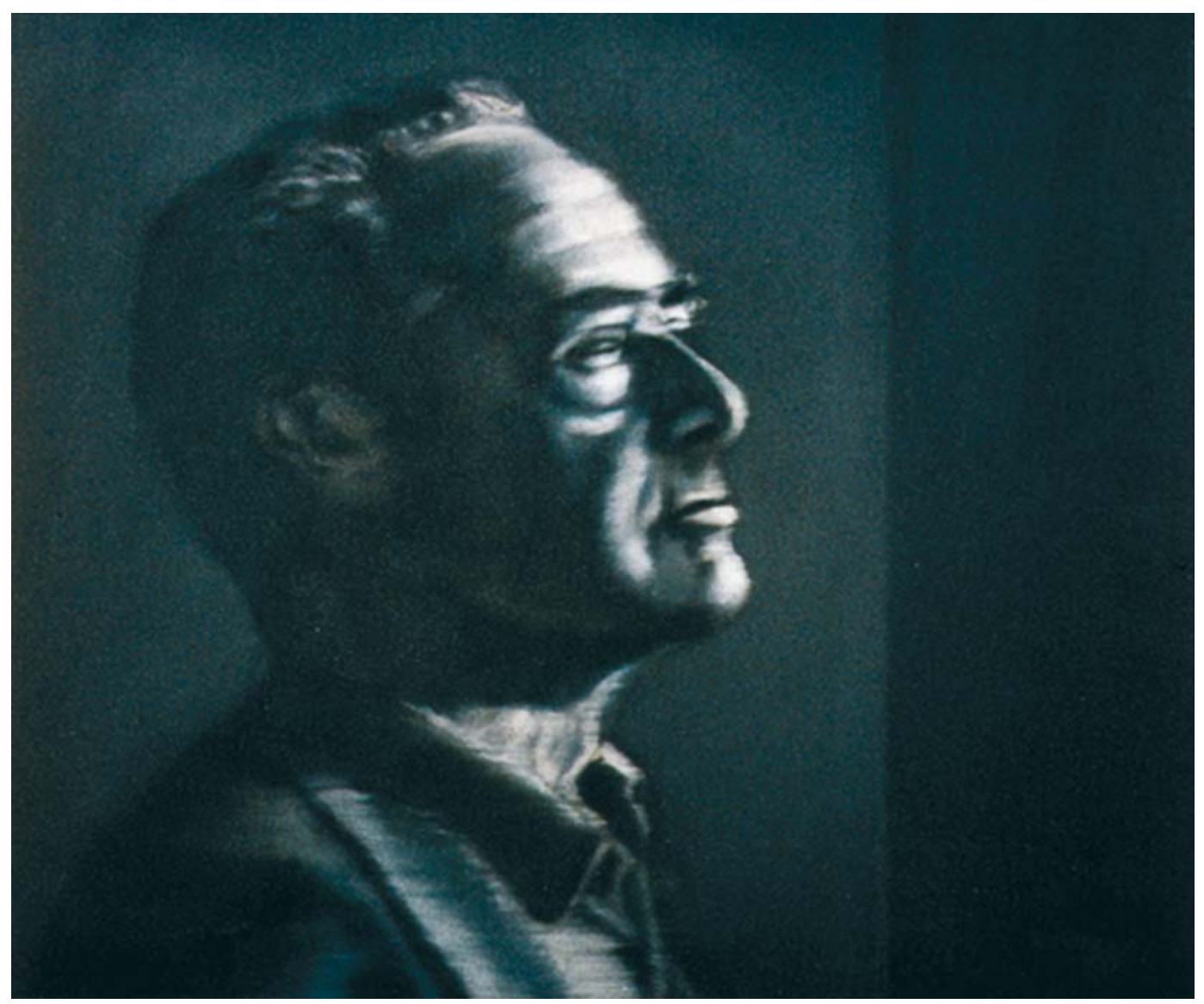

Figure 1: Richter, oil on canvas, $80 \times 100,1998$.

possible equivalent for indifference, non-commitment, absence of opinion [7].' This seems to fit neatly into Batchelor's analysis of a Western tradition, suppressing the subjective realm of the senses (and colour) in favour of the objective realm of the mind (and form), which in turn has led to painting's subordination in favour of photography. Barthes sees colour as 'a coating applied later on to the original truth of the black-and-white photograph . . . colour is an artifice, a cosmetic (like the kind used to paint corpses) [8].' However, Richter sees black-and-white photographs as no closer to the truth. To him, they too are 'a cosmetic' that masks the transitory nature of life. By creating a hybrid that is neither photo nor painting, he reveals the photo as a constructed image - a painted fake - no truer to reality than painting itself. In tandem, the 'objective' gaze of the camera/viewer is deliberately obfuscated by blurring, introducing 'uncertainty, transience, incompleteness [7].' Our naïve faith in the supremacy of photography is subverted.

Richter's photo-paintings are neither photograph nor painting, objective nor subjective, rational nor emotive, clear nor obscure, real nor fake: they are liminal, ambiguously vague, hovering in the 'between'. They question 'fixed form, the posit sign' [7] thus uncovering the 'non-colour' grey, readily associated with the truth and reality, as perhaps the most deceptive colour of all. This rejection of 'the fixed' has kindled my preoccupation with iridescence. 

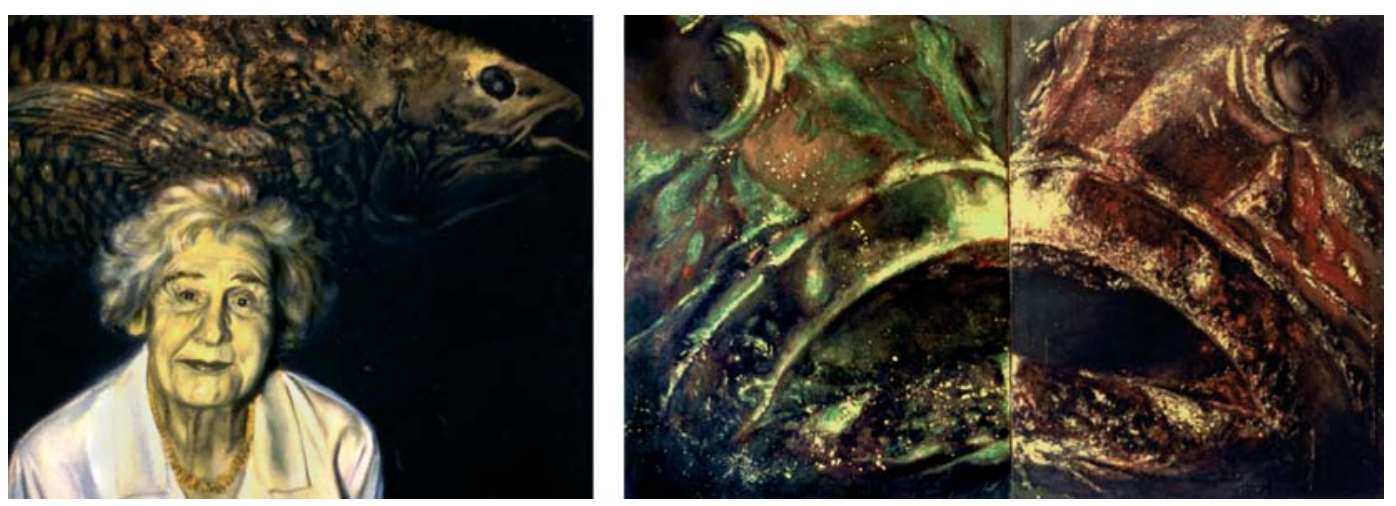

Figure 2: Latimeria, oil on canvas, $80 \times 100,1999$; and Denizen II, diptych, oil on canvas, $155 \times 240,1999$.

\subsection{Yellow into gold: the colour of icons}

As the millennium drew closer my photo-realism gradually turned into a sensibility - more akin to Moreau's (1826-1898) fine-de-siecle symbolism than Richter's conceptual restraint. My childhood fascination with water and its environs resurfaced. Terra firma transformed into a surreal underwater world of constant flux. Human portraits morphed into fish heads. Ageing became linked to evolution. And subtle shades of grey transmuted into yellow light piercing the dark.

This development was inspired by the coelacanth - an icon of modern evolutionary science. In 1938, the relic 'living fossil' fish, believed to have been extinct for over 65 million years, was rediscovered by Miss Courtenay-Latimer (Fig. 2). In 1998, the 'Story of the Coelacanth' took another unexpected twist - becoming a story of iridescence. A coelacanth was spotted in Indonesia - a remarkable find as the original population of the Comoros Islands had been believed to be unique [9]. Notably, the Indonesian coelacanth differs from its cousin in one crucial respect: it displays golden iridescence. Scientific findings suggest [10] that a fish previously thought untouched by time may have evolved into two species - one of which has adapted its colour to gold (Andrew Parker, in preparation).

In alchemy, the precursor to modern science, gold symbolises physical, mental and spiritual perfection, which the alchemist sought by transmuting base metals into gold [11]. Historically, for centuries, in Christian art gold remained restricted to icon painting, depicting the Devine. However, in the last century Warhol consciously appropriated this tradition in Gold Marilyn (1962), one of an extended series of screen-prints from the year of Monroe's death. In my work of the late 1990s, the lower strata of nature takes centre stage, replacing human beings. To elevate mute, expressionless fish to iconic status may be seen as grotesque and defiling - but, after all, we originate from the sea. The large fish heads, featured in the various series (Figs. 2 and 3), 'float' between abstraction and recognition. When viewed close up they dissolve into fragments; from afar their hollow eyes and gaping mouths come into focus. 'One' fish becomes a multitude of mirror-images simultaneously beguiling and frightening, familiar and alien, ancient and contemporary, prey and predator but most of all - ambiguously enigmatic. The yellow background colour, traditionally seen as positive, here has ambivalence, coming from behind with an acidic quality, disintegrating the images. The darker side of gold - excess, corruption, decadence - is evoked. 

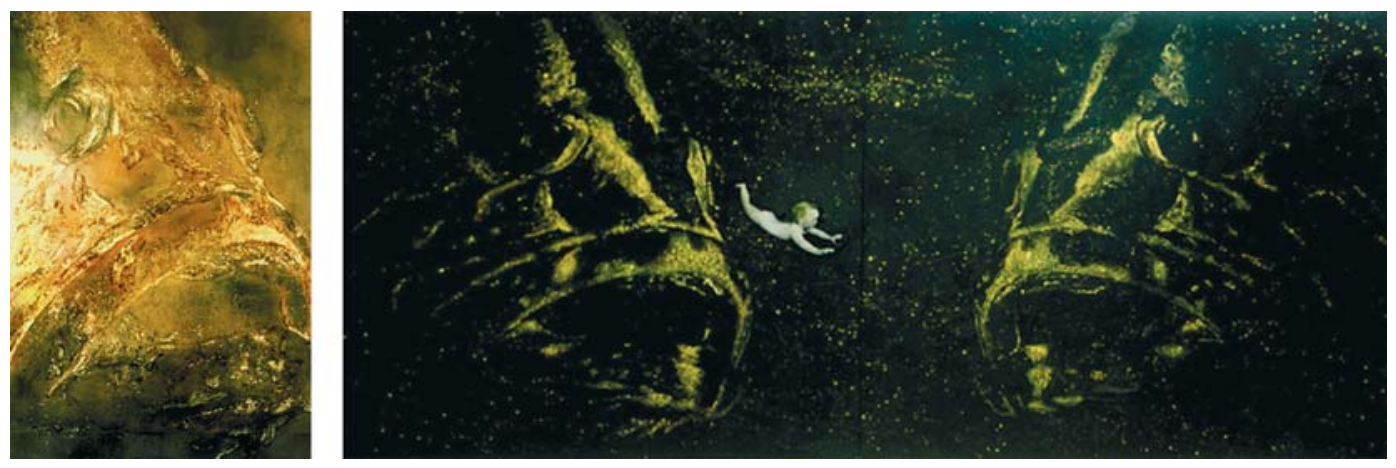

Figure 3: Denizen I, oil on canvas, $155 \times 120,1999$; and Skulduggery, diptych, oil on canvas, $180 \times$ $425,1999$.

To create the illusion of gold, I relied on conventional oil paints. However, not entirely suited to the task, these rather dull paints, based as they are on chemical pigments, proved far from ideal [12]. The vivid golden and more familiar silver beams of iridescence generated by many fish, on the other hand, appear identical to the actual precious metal. Yet, surprisingly, neither gold nor silver traces are found in their scales/skin. The metallic-like colour perceived is the result of transparent nano-scale multi-layer reflectors interacting with light [13]. Nature has been transmuting ordinary matter into noble metals for millions of years. As can be expected this 'fool's gold', when finally resolved by science, kindled a gold rush in industry. From the mid-20th century the race was on to develop commercially viable synthetic versions. This led to a breakthrough in the 1970s when a first generation of iridescent flakes that, like fish, mimic precious metals via the phenomenon of light interference, was introduced [14]. While they are still mainly in use today, essentially all this early mica-based technology equates to is, in effect, a single-layer reflector: a pale imitation of Nature's much more complex and sophisticated multi-layer reflectors.

\section{IRIDESCENCES}

However, at the beginning of the 21st century, fuelled by the rapid advancements of nano-science and nano-manufacturing, the evolution of iridescent technology is gaining considerable momentum. An ever-expanding range of second-generation iridescent flakes, no longer based on mica, has been introduced. Their novel multi-layered thin film structure generates purer, more intense interference colours and, in some instances, distinct colour travel [3]. Their rise to prominence in specific facets of industry has been driven by commercial interest with applications in the motor, cosmetics, fashion and printing industries paramount. Yet most of the excitement seems to have bypassed fine art painting. While this is partly due to a lack of awareness and availability, together with high cost involved, the major drawback is surely the challenge the actual creative application presents. As iridescent flakes are optical devices governed by the rules of additive colour theory (based on the primaries red, blue and green) the established methods of easel painting no longer apply. Their conversion to painting requires something truly innovative.

\section{1 'Chameleonesque' colour: the colour of change}

In 1999, this technology came to my attention in a chance conversation at the opening of 'Beginnings' (my group show at the Whitworth Gallery, Manchester). At the time I was working on a series 

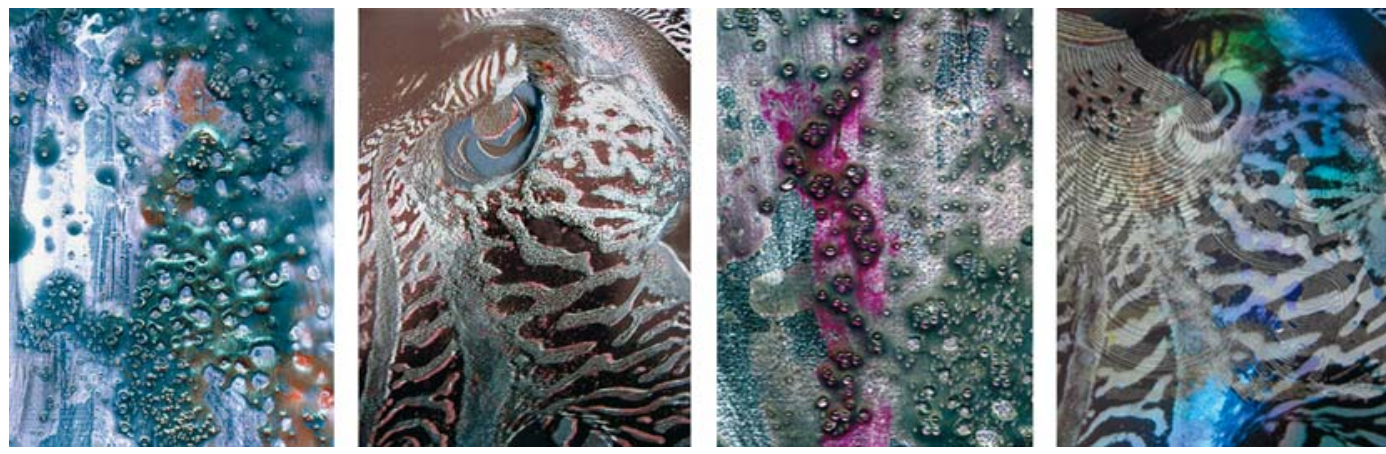

Figure 4: Studies of Cuttlefish, mixed media (beads, wax and iridescent paint), A4, 2003-2006.

inspired by the chameleon's subtleties of transformation. A representative from a leading pigment manufacturer suggested latest colour-shift flakes might be pertinent. Having been provided with the flakes by the manufacturer it, in fact, subsequently took me several years to gain a basic understanding of the optical principles involved and transform the raw material, ironically a grey powder, into a medium suitable for painting.

By 2004, I was at last ready to introduce the new technology into my work. While artist in residence at the National Marine Aquarium Plymouth I had, with increasing fascination, observed that unsung hero, the cuttlefish. Perpetually metamorphosing, this 'Chameleon of the Sea' features a continuously changing display of kaleidoscopic colour, pattern and texture. In an instant, waves of colour can flow across its entire body, changing hue from maybe green to violet and back again - a dynamic flow of oscillating colour never seen in painting. Yet, the prejudice still lingers, that: 'Intelligent beings have a language represented by articulate sounds ... colour, then, is the peculiar characteristic of the lower forms of nature. [15].' However, while 'mute', here, colour has become a complex language [16] supported by a colour 'technology' so sophisticated that it equals, if not surpasses, that of our digital age [1]. In loose analogy to a television screen, cuttlefish skin contains individually adjustable 'sub-dots'/ cells (the beads in Sea Change, Fig. 5). These cells are (chemical) primary-colour-units that switch on (expand) and switch off (contract), or remain in between, thus (in combination) assuming any colour desired via optical mixing. In addition, iridescent 'mirror' cells reflect colours from the surroundings.

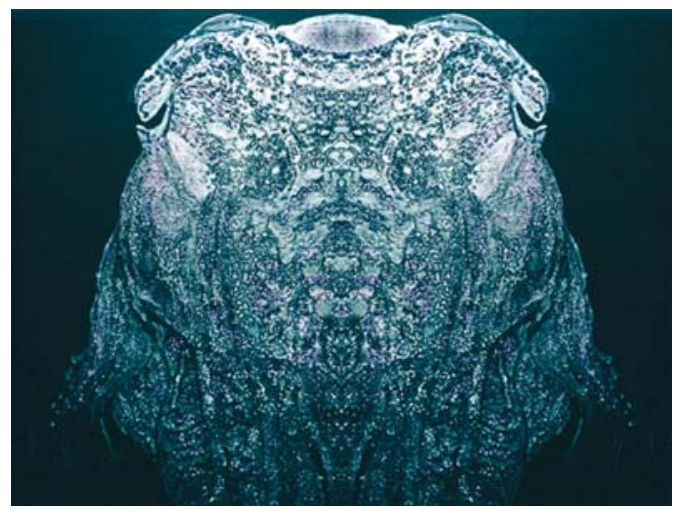

Figure 5: Sea Change, diptych, iridescent paint and beads on board, $90 \times 120,2006$. 


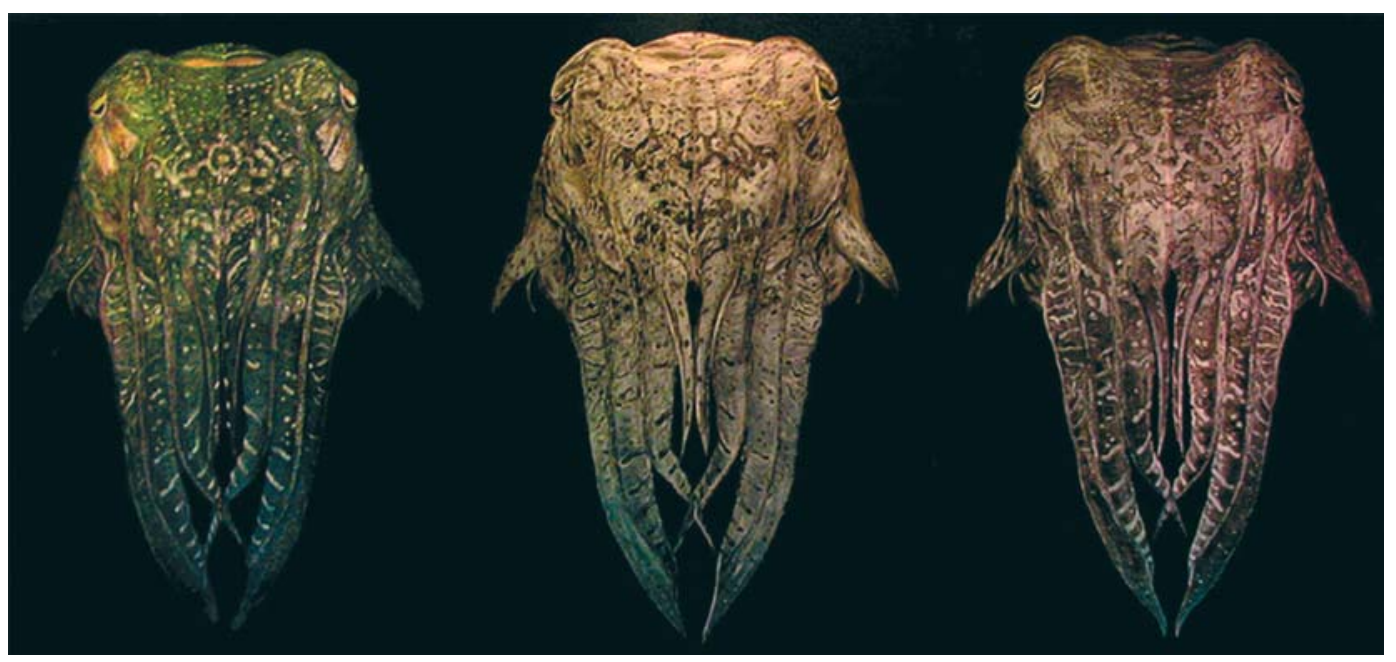

Figure 6: Mantle of many Colours, triptych, iridescent paint on board, $120 \times 275,2004$.

But how can one 'represent' such an elusive (or rather illusive) creature in painting? Which of the many mantles reveals its 'true' self, its very 'essence'? As with previous work, this 'fugitive' in ever-changing disguise seemed to make more sense in the context of a series, in which each 'individual' image mirrors one of its many appearances. But now I also had colour-variable hues on my palette. A subtype of multi-layer reflector, the flakes' layers vary in thickness, each reflecting a different wavelength, thus generating a flow of colour that, for example, shifts from green to violet and back again.

Meticulous and time-consuming research on my part (Fig. 4) eventually led to a triptych, 'representing' the cuttlefish in its many guises (Fig. 6). The desired 'chameleonesque' effect was achieved. The resulting paintings fluctuate in perceived colour, depending both on light variation and the angle of vision [12].

\subsection{Morpho blue: the colour of 'heavenly' jewels}

Captivated by their ephemeral beauty, fragility and capacity for continuous transformation, I have recently turned my attention to butterflies. Crucially in their race for survival, many of these short-lived creatures dazzle with vibrant displays of jewel-like colour. The Ancient Greeks borrowed their wings for Psyche, the lovely maiden symbolising the human soul rising towards the 'great beyond'. Many butterflies carry 'heavenly' blue on their wings. However, the exotic Morpho butterfly - its dramatic, dynamic and dazzling metallic blue visible for a quarter of a mile - is perhaps the most spectacular. Klots [17] describes Morphos as 'jewels' generating flashes of 'almost three-dimensional . . . living' colour. What seems poetic licence has recently been proven: some butterfly scales indeed contain optical devices that resemble those of actual jewels [18] and, like these, do not tarnish. Not surprisingly, such 'living' colour has never been replicated in the art world, not even in the form of highest-definition photographs or digital prints.

Painters of the past have perhaps come closest. In the late middle ages, the most precious of artists' materials, often exceeding the price of gold, was natural ultramarine blue. Extracted from the gemstone lapis lazuli, it was reserved for the Virgin's cloak - symbolising the heavenly and spiritual [19]. Titian used the purest lapis lazuli pigment for the sky in Bacchus and Ariadne [20]. However, Moreau's symbolist painting Jupiter and Semele (1895) might be the most excessive homage to the 
gem yet. Picking up the sky's electric blue to animate the drama, every surface in this opulent palace scene is encrusted with lapis lazuli stone. Semele has just given birth to Bacchus, the god of intoxication, in the process opening the portals to an inner world: 'the minds antipodes' where colour is gem-like, at its very purest, uncorrupted by reason and language [5]. Klein's 1950s attempt to capture such transcendental qualities in monochrome blue canvases was hampered by the dull synthetic ultramarine employed.

However, now, thanks to latest iridescent technology painters have a truly gem-like, luminous blue at their potential disposal. This subtype of multi-layered reflector features layers of uniform thickness, reflecting the same wavelength repeatedly, each time further amplifying the colour's intensity [3]. Just as the Morpho butterfly [21] has inspired this man-made technology, it can also teach us how best to employ it. Close microscopic examination of the mechanisms creating the brilliant blue colouration in the Morpho has helped me to go some way in reproducing the colour in painting. The resulting micrograph-paintings owe much to Richter. They slavishly subordinate themselves to Nature as seen through the microscopic viewfinder. The 'natural' and 'organic' turn into something highly 'mediated', 'contrived' and 'artificial'. Yet, fluctuating colour injects life, movement and beauty. Not unlike Richter's blurring, such colour destabilises the mechanical, objective, clinical gaze of technology/science. The effect is surreal, an impure mixture of confusion and bedazzlement.

Morpho blue is not a passive coating. Resembling gems, this 'colour is active: it is alive. Colour projects . . light appears to shine from within; colour seems to have its own power source.' [5]. But more than that, Morpho blue also shifts hue; and even vanishes from sight when the light strikes the wing (and painting) at a certain angle, leaving a dull brown innocuous butterfly: a magical effect, at once surprising and disturbing (Fig. 7). Almost by default the blue iridescence exposes itself as 'an artifice, a cosmetic' that temporarily vanishes/reappears to reveal/veil the 'true' brown butterfly. Colour and tonal base at times become indistinguishable though, simultaneously, each element remains intact, discrete and autonomous. Colour appears independent from its base, but is entirely dependent on it. Without the dark sub-layer the blue loses all its vibrancy. Here, colour is at once primary and secondary; alive and dead; fluid and stable; flamboyant and plain; ephemeral and permanent; natural and artificial.

Such colour is no longer singular but multiple, perpetually metamorphosing. This can be at once disturbing and compelling, particularly when encountered in painting - traditionally a static medium associated with the freezing of time, preservation and permanence. The pictorial coherence and unity, together with the single vantage point, is unhinged and destabilised. Perhaps, this really is 'the point at which colour becomes assertive - or disruptive and excessive' [5] as Batchelor claims for
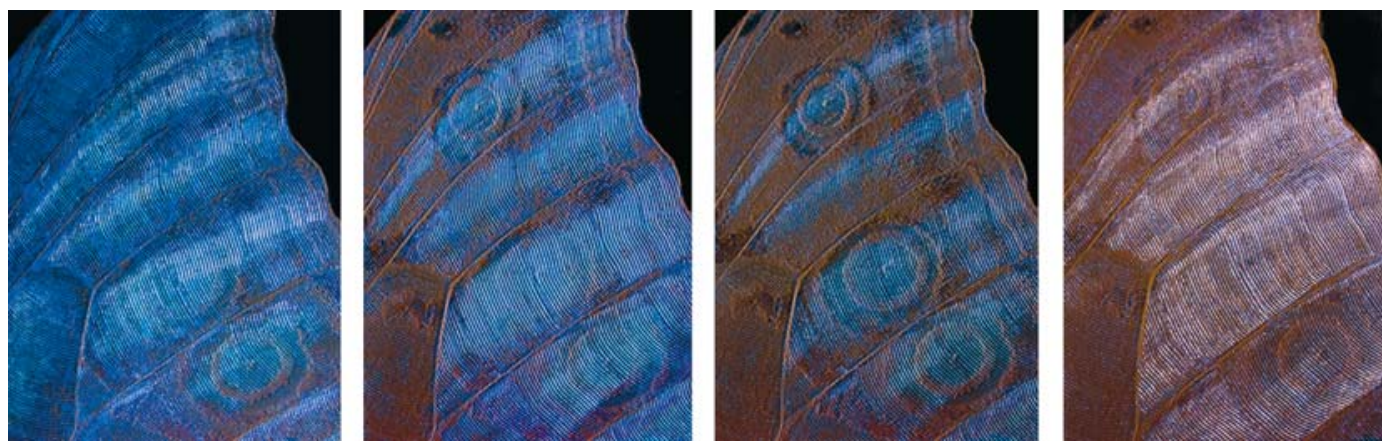

Figure 7: Morpho Butterfly, wing detail, A4, 2008. The same iridescent painting lit from four angles. 

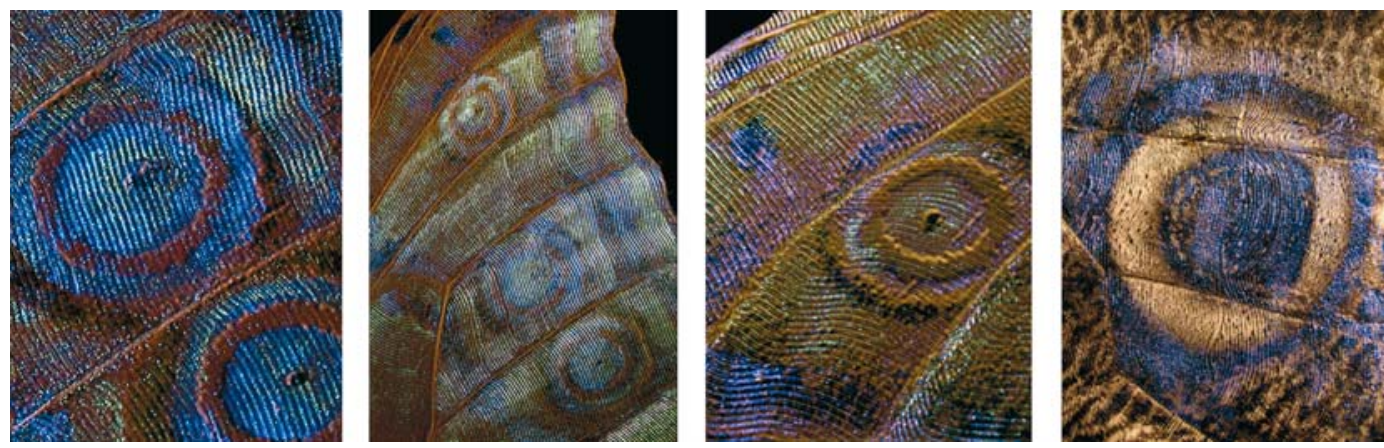

Figure 8: Eyespot Paintings, mixed media and iridescent paint on board, A4, 2007-2008.

gems. However, while subverting logic, clarity and certainty, the spectacle of iridescence simultaneously appeals to the senses, demanding the viewers' attention and involvement. Similarly, in Nature iridescence has a double quality: it is designed to seduce and impress, but also to startle and frighten. Fluctuating colour can pose a disturbance, and perhaps even a danger, a threat; certainly much more so than the 'stable', dull, lifeless chemical colours ever can achieve; and perhaps even more so than gems. If Batchelor is right, this glittering, fleeting, changeable colour could be destined to provoke strong resentment from chromophobic circles. However, any denunciation of iridescence as decadent, bizarre, excessive, vulgar, kitsch, cosmetic and thus unworthy of serious consideration would only confirms the colour's potency.

\section{CONCLUSION: IRIDESCENCE AND THE FUTURE}

Fluctuating colour is hard to enlist, control, make sense of and put to artistic practice. It is governed by optical principles that differ significantly from those of chemical pigments. The established rules of easel painting no longer hold. New rules and working methods have to be established [22]. The theoretical principles of physical optics, while crucial, do not alone solve the many challenges that practical application presents. However, as iridescent creatures have inspired the technology, so they can also teach us how to best employ it. Aided by scientists at the Natural History Museum, London and the University of Birmingham, I have carefully scrutinised the iridescence-inducing mechanisms of selected butterflies. With their invaluable support I have made considerable strides in overcoming the many technical challenges inherent in applying the technology to art (Fig. 8). While much remains to be resolved, the biomimetic approach developed and employed by the author is yielding promising results. But, no doubt, others are currently investigating equally valid methods of application.

As regards positioning iridescence within the wider multidisciplinary discourse on colour, as far as I am aware, to date little has been undertaken in this area. Potentially an active, 'living' colour that changes with every shift of light or angle of view; that vanishes and reappears; that advances with an intensity never seen in art before, might simply refuse to be rationalised and pinned down. To my mind any appreciation, whether scientific and/or artistic ought to consciously embrace change, transience and flux, together with the ambiguous, mysterious and subjective. A tall order indeed. There are signs though that such a Zeitgeist might be emerging. Scientists are beginning to integrate iridescence's more maverick and enigmatic qualities into their enquiry, acknowledging that it belongs to 'the free realm of beauty' [23] created by 'unknown forces of life' [2]. In this spirit, my artistic practice draws on latest scientific findings which illuminate natural iridescence to increase our awe and 
reverence for Nature's ingenuity 'which creates beauty and splendor that exceeds all functional need and purpose' [2].

Can we therefore predict a sparkling future for iridescence in art? Presciently, in 1999 Koolhaas foresaw that 'colour could make a comeback ... simply through the impact of new technologies and new effects. In a world where nothing is stable, the permanence of (chemical) colour is slightly naïve; maybe it could change' [24]. And indeed colour has changed. Referring to colour-shift flakes, Ball [19] confirms: 'Certainly I think all these media will be used - because that is the way of art, to find ways to take advantage of what technology has to offer; ... technology opens new doors for artists.' And Nature, it would seem, continues to open even more.

\section{ACKNOWLEDGMENTS}

This research was supported by the Arts Council of England and the Arts and Humanities Research Council (AHRC).

\section{REFERENCES}

[1] Parker, A., In the Blink of an Eye: How Vision Kick-started the Big Band of Evolution, Free Press: London, p. 109, subsequent quotation is from p. 91, 2003.

[2] Simon, H., The Splendor of Iridescence, Dodd, Mead \& Company: New York, p. 172, subsequent quotations are from p. 236 and the preface, 1971.

[3] Pfaff, G., Optical principles, manufacture, properties and types of special effect pigments (Chapter 2). Special Effect Pigments, ed. G. Pfaff, 2nd edn, Vincentz Network: Hannover, pp. 72-83, 2008.

[4] Von Weizsäcker, C.F., forword to Heimendahl, E., Licht und Farbe: Ordnung und Funktion der Farbwelt, Walter de Groyter: Berlin, 1961, quoted in Simon [2], p. 237.

[5] Batchelor, D., Chromophobia, Reaktion: London, p. 23, subsequent quotation is from p. 74, 2000.

[6] Gage, J., Colour in Art, Thames and Hudson: London, p. 15, 2006.

[7] Richter, G., The Daily Practice of Painting, Thames and Hudson: London, p. 22, subsequent quotations are from p. 58, 82, 73 and 80, 1995.

[8] Barthes, R., Camera Lucida: Reflections on Photography, Hill and Wang: New York, p. 81, 1981.

[9] Weinberg, S., A Fish Caught in Time, Fourth Estate: London, 1999.

[10] Holder, M.T., Erdmann, M.V., Wilcox, P., Caldwell, R.L. \& Hillis, D.M., Two living species of coelacanths? PNAS, 96(22), pp. 12616-12620, 1999. doi:10.1073/pnas.96.22.12616

[11] Gage, J., Colour and Culture, Thames and Hudson: London, p. 139, 1993.

[12] Schenk, F. \& Harvey, J., Reflections on the natural history museum: the art of iridescence and nature's jewels. Int. J. of the Arts in Society, 3(5), pp. 133-144, 2009.

[13] Parker, A., 'Simple' optical reflectors in animals. Structural Color in Biological Systems, eds S. Kinoshita \& S. Yoshioka, Osaka University Press: Osaka, p. 46, 2005.

[14] Greenstein, L.M., Nacreous (Pearlescent) Pigments and Interference Pigments. The Pigment Handbook, 2nd edn, Vol. 1, Wiley: New York, pp. 829-857, 1988.

[15] Blank, C., The Grammar of Painting and Engraving, 1867. Colour, ed. D. Batchelor, Whitechapel: London, and MIT Press: Cambridge, Massachusetts, pp. 32-34, 2008.

[16] Hanlon, T.R. \& Messenger, J.H., Cephalopod Behaviour, Cambridge University Press: Cambridge, pp. 120-131, 1996.

[17] Klots, A.B., Living Insects of the World, Doubleday: New York, 1959, quoted in Simon [2], p. 198. 
[18] Vukusic, P., Structural colour effects in Lepidoptera. Structural Color in Biological Systems, eds S. Kinoshita \& S. Yoshioka, Osaka University Press: Osaka, p. 107, 2005.

[19] Ball, P., Bright Earth: The Invention of Colour, Vintage Books: London, p. 265, subsequent quote is from p. 384, 2008.

[20] Bomford, D., The history of colour in art, Colour: Art \& Science, eds T. Lamb \& J. Bourriau, Cambridge University Press: Cambridge, p. 20, 1995.

[21] Berthier, S., Iridescences: The Physical Colors of Insects, Springer: London, p. 88, 2007.

[22] Schenk, F. \& Parker, A., Iridescent Colour: From Nature to the Painter's Palette, Leonardo, in press.

[23] Portmann, A., The Beauty of Butterflies, B.T. Batsford: London, 1951, quoted in Simon [2], p. 238.

[24] Koolhaas, R., The Future of Colours is Looking Bright, 1999. Colour, ed. D. Batchelor, Whitechapel: London, and MIT Press: Cambridge, Massachusetts, pp. 219-220, 2008. 